\title{
Application of the powder of porous titanium carbide ceramics to a reusable adsorbent for environmental pollutants
}

\author{
Hiroshi Moriwaki* ${ }^{1}$, Shiori Kitajima ${ }^{1}$, Koji Shirai ${ }^{1}$, Kenji Kiguchi ${ }^{1}$, Osamu Yamada ${ }^{2}$
}

${ }^{1}$ Shinshu University, Faculty of Textile Science and Technology, Division of Applied Biology, 3-15-1,

Tokida, Ueda 386-8567, Japan, E-mail: moriwaki@shinshu-u.ac.jp

2 Osaka Sangyo University, Research \& Development Center for New Industry, 3-1-1, Nakagaito, Daito 574-8530, Japan

\footnotetext{
* To whom correspondence should be addressed.

E-mail: moriwaki@shinshu-u.ac.jp
} 


\section{Abstract}

The aim of this study is to investigate the utilization of the powder of porous titanium carbide (TiC) ceramics as a novel adsorbent or a material for solid-phase extraction (SPE). The adsorption and elution of inorganic and organic pollutants, $\mathrm{Pb}$ (II), 2,4,6-trichlorophenol (TCP), perfluorooctane sulfonate (PFOS), and perfluorooctanoic acid (PFOA), to the material were evaluated. The cartridge packed with TiC ceramics powder was used for the extraction test of pollutants. The solution containing pollutants at $1.0 \mu \mathrm{g} / \mathrm{mL}$ was passed through the $\mathrm{TiC}$ cartridge, and the substances were almost quantitatively removed. Furthermore, the pollutants retained in the cartridge were eluted with $3 \mathrm{~N} \mathrm{HCl}$ for $\mathrm{Pb}(\mathrm{II})$ and with methanol for organic pollutants. The recoveries of pollutants were over $80 \%$. In addition, we used the TiC cartridge for the solid-phase extraction of water samples $(500 \mathrm{~mL}$ each of the distilled water and the river water) by adding pollutants at determined concentrations. Every pollutant was adsorbed almost quantitatively, and eluted by $3 \mathrm{~N} \mathrm{HCl}$ or methanol. From these results, we concluded that the powder of porous $\mathrm{TiC}$ ceramics is a useful reusable adsorbent for the water cleanup and solid-phase extraction.

Key words: TiC, porous ceramics, combustion synthesis, water clean-up, solid-phase extraction, reusable adsorbent 


\section{Introduction}

Quality maintenance of drinking and environmental water is very important in order to avoid toxic influences of contaminants on human beings and living creatures. For the conservation of water safety, the improvements and further developments of water treatment and analytical techniques have been needed.

Adsorbents have been playing an important role for the clean-up process of waste water, and various materials have been developed as adsorbents [1,2]. Activated carbon, in particular, has been widely used as a typical adsorbent material for the clarification of water [3-5]. The material is a microporous adsorbent and is very useful for the removal of various pollutants. However, the interaction between the activated carbon and pollutants are generally very strong, thus making it difficult to elute adsorbed matters and to recycle activated carbon at a low cost [6]. This leads to the generation of huge quantity of toxic sludge. Therefore, the development of the adsorbents, which can not only remove pollutants and elute the adsorbed matters, but also be reused, has been needed.

Adsorbents have been also used as the material for solid-phase extraction (SPE) in an examination of water. SPE has been applied to various analyses, such as environmental monitoring [7-9], food analysis [10-12], and biochemical analysis [13-15]. Octadecyl-bonded silica gel (ODS) has been widely used as an adsorbent of organic compounds for SPE [16]. ODS can sorb wide range of organic compounds and elute them by organic solvents, such as methanol and acetonitrile. However, there are several limits for the use of ODS, such as the range of $\mathrm{pH}[17,18]$.

Our research group developed porous titanium carbide (TiC) ceramics [19]. The ceramics has been fabricated from the reactants of titanium powder and carbon fiber by the combustion synthesis method. There were several reports concerned with the preparation of porous carbide ceramics, such as silicon carbide, zirconium carbide, titanium carbide, and hafnium carbide [20-23]. In this study, we focus on porous $\mathrm{TiC}$ ceramics, because the costs of raw materials are relatively low, and the 
preparation method was established. It is anticipated that porous $\mathrm{TiC}$ ceramics shows adsorption activity like activated carbon, because it contains carbon and has porous structure. In addition, the material would be able to be washed by various solvents and be reused, because ceramic materials show high persistency. Therefore, it is thought that TiC ceramics has a potential to be a useful and unique adsorbent for the clarification of environment and SPE.

Several researches concerned with the use of ceramics material as adsorbents for the clarification of environment was presented [24]. However, there were very few examples which applied porous carbide ceramics to water treatment [25]. In this study, we investigated the utilization of the powder of porous $\mathrm{TiC}$ ceramics as a novel adsorbent for the removal of pollutants from water and the solid-phase extraction. The object substances for adsorbates to $\mathrm{TiC}$ ceramics were $\mathrm{Pb}(\mathrm{II})$, 2,4,6-trichlorophenol, and perfluorinated compounds. It is well known that lead is a highly toxic element and has been extensively used in the modern industry to manufacture products, such as lead-acid batteries, radiation shields, gasoline, and paint. 2,4,6-Trichlorophenol is a chlorinated phenol that has been used as a fungicide, herbicide, and insecticide. It is carcinogenic in animals, causing lymphomas, leukemia, and liver cancer via oral exposure. Perfluorinated compounds, perfluorooctane sulfonate (PFOS) and perfluorooctanoic acid (PFOA), have been used in a variety of consumer and industrial applications, and are shown to be globally distributed, environmentally persistent and bioaccumulative. $\mathrm{Pb}(\mathrm{II})$, 2,4,6-trichlorophenol, $\mathrm{PFOS}$ and $\mathrm{PFOA}$ have been found in water environment, and it is important to get further information about their distribution in the environment.

\section{Experimental}

\subsection{Materials}

TiC ceramics was obtained from O.S.U. (Osaka, Japan). TiC ceramics was crushed by a jaw crusher 
(Fritsch Japan, Kanagawa, Japan), and sieved. TiC ceramics powder with the grain size of 45-75 $\mu \mathrm{m}$ was used for the adsorption test in this study. The surface area of the powder was $2.77 \mathrm{~m}^{2} \mathrm{~g}^{-1}$. Sodium hydroxide, hydrochloric acid, lead nitrate (II), nitric acid, 2,4,6-trichlorophenol (TCP), methanol, acetonitrile, acetic acid and ammonium acetate were purchased from Wako Pure Chemical Industries (Osaka, Japan). PFOS and PFOA were obtained from Tokyo Kasei (Tokyo, Japan). Sodium dodecyl- $\mathrm{d}_{25}$ sulfate (SDS- $\mathrm{d}_{25}$ ) was from CDN isotopes (Quebec, Canada). Distilled water was produced by an automatic water distillation apparatus (NANOpure II, Barnstend, Boston, MA, USA).

\subsection{Extraction test}

Polypropyrene syringe (Internal diameter: $12.5 \mathrm{~mm}$; VARIAN, PaloAlto, U.S.A.) was packed with porous $\mathrm{TiC}$ ceramics powder ( $2.0 \mathrm{~g}$ ), and polypropyrene frits (upper and lower) were used at each end of the cartridge to hold the packed TiC powder in place. The obtained column was used as the TiC cartridge. The height of $\mathrm{TiC}$ ceramics phase of the $\mathrm{TiC}$ cartridge was $8 \mathrm{~mm}$. The stacking density of the TiC cartridge was $5.0 \mathrm{~g} \mathrm{~cm}^{-3}$. In order to avoid adsorption of metals to glass vessels, the $\mathrm{pH}$ level of the metal solutions was set at 5 for the adsorption test of TiC ceramics [26]. The $\mathrm{pH}$ of the solutions was adjusted with $\mathrm{HCl}$ and $\mathrm{NaOH}$. For the $\mathrm{Pb}(\mathrm{II})$ extraction and elution test, the procedure was as follows: TiC cartridge was pre-conditioned with $20 \mathrm{~mL}$ of $\mathrm{HCl}(3 \mathrm{~N})$ first, then with $30 \mathrm{~mL}$ distilled water (pH 7), and lastly with $10 \mathrm{~mL}$ distilled water (pH 5). Next, $10 \mathrm{~mL}$ of the water sample solution, which was spiked with $10 \mu \mathrm{g}$ of $\mathrm{Pb}(\mathrm{II})$ and adjusted to $\mathrm{pH}$ 5, was put through the cartridge. The flow rate was at $10 \mathrm{~mL} \mathrm{~min}^{-1}$. Subsequently, the retained $\mathrm{Pb}$ (II) was eluted with 10 $\mathrm{mL}$ distilled water $(\mathrm{pH} \mathrm{5})$ and $30 \mathrm{~mL}(10 \mathrm{~mL} \times 3)$ of $3 \mathrm{~N} \mathrm{HCl}$. The eluent was measured for the quantitative determination of $\mathrm{Pb}(\mathrm{II})$ by ICP emission spectrometry.

The extraction and elution test of organic pollutants was performed as follows: TiC cartridge was pre-conditioned with $20 \mathrm{~mL}$ of methanol first, then with $10 \mathrm{~mL}$ distilled water (pH 7), and lastly with 
$10 \mathrm{~mL}$ distilled water $(\mathrm{pH} 5)$. Next, $10 \mathrm{~mL}$ of the water sample solution, which was spiked with 10 $\mu \mathrm{g}$ of TCP, PFOS, and PFOA, and adjusted to $\mathrm{pH} 5$, was put through the cartridge. The flow rate was set at $10 \mathrm{~mL} \mathrm{~min}{ }^{-1}$. Subsequently, the retained pollutants were eluted with $10 \mathrm{~mL}$ distilled water $(\mathrm{pH}$ 7) and $30 \mathrm{~mL}(10 \mathrm{~mL} \times 3)$ of methanol. The eluent was measured by liquid chromatography/mass spectrometry (LC/MS). Moreover, in order to observe the reusability of TiC ceramics as adsorbent for pollutants, the extraction test was repeated 5 times by using the same TiC cartridge.

Commercially available activated carbon cartridge AC2 (Sep-Pak plus; Waters, Milford, MA, USA) was used for the comparison of the adsorption behavior with the TiC cartridge. Extraction tests using $\mathrm{AC} 2$ were also performed by the same procedure as the TiC cartridge.

\subsection{Batch experiments}

The adsorption capacities and isotherms for $\mathrm{Pb}(\mathrm{II}), \mathrm{TCP}$, PFOS, and PFOA were determined in batch adsorption experiments. Batch experiments to determine adsorption capacities were carried out under various conditions of the initial concentration of $\mathrm{Pb}(\mathrm{II})$ or $\mathrm{TCP}$, the quantity of $\mathrm{TiC}$ ceramics powder, and the agitation time. All batch experiments were conducted under ambient conditions.

TiC ceramics powder and 25 or $100 \mathrm{~mL}$ distilled water containing $\mathrm{Pb}(\mathrm{II})$ or TCP were added to each flask. Next, the solutions were stirred at $158 \mathrm{rpm}$ by shaker. The tested suspension was filtered with cellulose membrane with pore size $0.45 \mu \mathrm{m}$ (Millipore Corporation, Bedford, U.S.A), and the filtered solution was used for measuring $\mathrm{Pb}(\mathrm{II})$ and $\mathrm{TCP}$ concentration. The adsorptions of $\mathrm{Pb}(\mathrm{II})$ and TCP to the cellulose membrane were not observed under the condition of the experiments.

\subsection{Solid-phase extraction using TiC ceramics}

Recovery tests were carried out using water samples $(500 \mathrm{~mL})$ spiked with $\mathrm{Pb}$ (II) and organic pollutants. Distilled water and river water were used as samples. River water was sampled from Chikuma River on $13^{\text {th }}$ October and $30^{\text {th }}$ November, 2009. The river water samples were filtered through a cellulose membrane with pore size $0.45 \mu \mathrm{m}$ (ADVANTEC, Tokyo, Japan) immediately 
after the sampling, and they were adjusted to $\mathrm{pH}$ 5. The samples were maintained in glass containers, and stored at a temperature of $4{ }^{\circ} \mathrm{C}$. The pre-condition procedure of the TiC cartridge, the extraction and elution procedures were the same as described above. The sample was put through the TiC cartridge by a micro tube pump (EYELA, Tokyo, Japan) at $10 \mathrm{~mL} \mathrm{~min}^{-1}$.

\subsection{Analytical procedure}

$\mathrm{Pb}$ (II) concentrations in solutions were measured by ICP emission spectrometer SPS 3100 (SSI nanotechnology, Tokyo, Japan; experimental operating parameters: RF power: $1.2 \mathrm{~kW}$; plasma gas flow rate (Ar): $16 \mathrm{~L} \mathrm{~min}^{-1}$; carrier gas flow rate: $1.0 \mathrm{~L} \mathrm{~min}^{-1}$; auxiliary gas flow rate: $1.0 \mathrm{~L} \mathrm{~min}^{-1}$ ). Working wave lengths for lead was $220.353 \mathrm{~nm}$. The detection limit of $\mathrm{Pb}(\mathrm{II})$ was $30 \mu \mathrm{g} / \mathrm{L}$.

The concentrations of organic compounds in solutions were analyzed using LC/MS technique. LC/MS 2010A (Shimadzu, Kyoto, Japan) was used for LC/MS measurement. L-column ODS (Chemicals Evaluation and Research Institute, Tokyo, Japan: $5 \mu \mathrm{m}$ particle size, $2.1 \times 150 \mathrm{~mm}$ i.d.) was used for the LC separation of 2,4,6-TCP, PFOS and PFOA. The HPLC separation was carried out at $40{ }^{\circ} \mathrm{C}$ using a gradient composed of solution $\mathrm{A}(1 \mathrm{mM}$ ammonium acetate solution adjusted to $\mathrm{pH} 4$ by the addition of acetic acid) and solvent B (acetonitrile). The gradient condition in solvent $\mathrm{B}$ was as follows: $0-5 \mathrm{~min}$, a linear increase from 5 to $80 \%$; 5-10min, a linear increase from 80 to

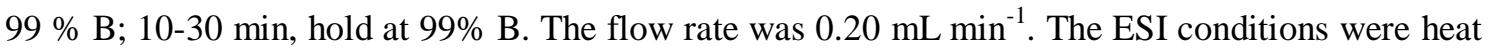
block temperature, $200^{\circ} \mathrm{C}$; interface voltage, $4.5 \mathrm{kV}$; CDL voltage, $20 \mathrm{~V}$. The sample solution $(0.5$ $\mathrm{mL}$ ) was mixed with 10 or $20 \mu \mathrm{l}$ of internal standard methanolic solution (sodium dodecyl sulfate- $\left.\mathrm{d}_{25}, 4 \mu \mathrm{g} / \mathrm{ml}\right)$. The solutions $(10 \mu \mathrm{L})$ were injected into the LC/MS system. The LC/MS acquisition was performed in the selected ion monitoring (SIM) mode at $m / z 195$ for TCP, $m / z 413$ for PFOA, $m / z 499$ for PFOS and $m / z 290$ for the internal standard. The detection limit of TCP, PFOS, and PFOA were 5, 0.1, and $0.1 \mu \mathrm{g} / \mathrm{L}$, respectively. 


\section{Results and Discussion}

\subsection{TiC ceramics}

TiC ceramics is a sintered material formed by combustion synthesis method from titanium and carbon powder $(\mathrm{Ti}: \mathrm{C}=1: 1)$ at $3000{ }^{\circ} \mathrm{C}$ [19]. It was found that the material was porous by the SEM measurement (Fig. 1), and the most frequent pore diameter observed by the babble point method using Perm-Porometer (PMI, BrainStorm, U.S.A) was $0.28 \mu \mathrm{m}$. So far, many kinds of porous ceramics materials, with pore diameters ranging from $\mathrm{nm}$ to $\mathrm{mm}$ have been developed. These materials have been applied to filters or catalyst supports, because they open up the fluid, and they have a large surface area [27]. In general, the pore diameters of activated carbons are nm level. The pore diameter of TiC ceramics is about hundred times larger than that of general activated carbons.

\subsection{Extraction ability of TiC ceramics}

In order to evaluate the extraction ability of porous $\mathrm{TiC}$ ceramic powder, the adsorptive removals of $\mathrm{Pb}(\mathrm{II})$, TCP, PFOS, and PFOA on TiC cartridge were studied. The results are shown in Table 1. Every pollutant was adsorbed almost quantitatively, and eluted over $80 \%$ by $30 \mathrm{~mL}$ of $3 \mathrm{~N} \mathrm{HCl}$ or methanol. Concerning with the elution of the organic compounds, the good recoveries were also obtained by the elution using acetonitrile. However, the values of recovery variability by the elution using acetonitrile were more than those using methanol, therefore we selected methanol as the eluate.

Similar adsorption-elution test was studied using a commercial activated carbon cartridge. The results are summarized in Table 2. $\mathrm{Pb}(\mathrm{II})$, TCP, PFOS, and PFOA were quantitatively absorbed on the cartridge, but the values of elution (\%) were lower compared to those by TiC cartridge.

When an adsorbent is used for the concentration, it is preferable that good recovery is achieved by the elution with a small amount of the eluate. However, the recoveries of TCP, PFOA, and PFOS 
with $10 \mathrm{~mL}$ of methanol were only 65,14 , and $39 \%$, respectively. It is expected that the elution behavior of an adsorbent would be improved by modifying the packing of $\mathrm{TiC}$ ceramics to the cartridge and the homogenization of diameters in the material.

Next, the adsorption and elution test using the same TiC cartridge was repeated 5 times in order to observe the reusability of the $\mathrm{TiC}$ cartridge. The results for $\mathrm{Pb}(\mathrm{II})$ are shown in Figure 2. The adsorption (\%) was $100 \%$, and the elution (\%) was approximately $80 \%$ through the adsorption-elution cycles (1-5 times). In the case of TCP, PFOS, and PFOA, the adsorption (\%) was $100 \%$, and the elution (\%) was over $80 \%$ through the adsorption-elution cycles (1-5 times). The results for TCP are shown in Figure 3. There was a tendency that the elution (\%) increased by repeating the adsorption-elution step. This would be caused by the elution of the retained target compounds in $\mathrm{TiC}$ cartridge at the previous adsorption-elution step. However, it is considered that TiC powder can be repeatedly used as an adsorbent to remove the target compounds from water by eluting them with appropriate solvents.

\subsection{Adsorption mechanism and capacity of TiC ceramics}

In order to discuss the adsorption capacities and mechanisms for $\mathrm{Pb}(\mathrm{II})$ and $\mathrm{TCP}$ to $\mathrm{TiC}$ ceramics, the adsorption isotherms were obtained by the batch test using TiC ceramics powder (Figure $\mathbf{4}$ and $\mathbf{5}$ ). The plots at the concentration of adsorbates $0-1000 \mu \mathrm{g} \mathrm{L}^{-1}$ showed a linear line for $\mathrm{Pb}$ (II) and a convex curve line for TCP. In general, the linearity of the adsorption isotherms at low levels of an adsorbate indicates that the partition between the adsorbent and the solution at a constant rate occurs. Therefore, $\mathrm{Pb}(\mathrm{II})$ would be partitioned between TiC ceramics and water at a constant rate, and that leads to the high recovery of $\mathrm{Pb}(\mathrm{II})$ adsorbed on the $\mathrm{TiC}$ cartridge by the elution of $\mathrm{HCl}$ solution.

A convex curve line of the adsorption isotherms at low levels of an adsorbate is shown in the case that there are some interaction between the surface of the adsorbent and the adsorbate, and the 
interaction between the adsorbent and a solvent is small [28]. Activated carbon generally shows the convex curve line of the adsorption isotherms for organic compounds because the material hydrophobically interacts with organic compounds. It is anticipated that TiC ceramics adsorb TCP with hydrophobic interaction as activated carbon. Pore size of the adsorbent has a significant effect on hydrophobic interactions on the solid phase [29]. The pore size of TiC powder is larger than that of the activated carbon (Table 2), and that would make the elution of pollutants on TiC easier.

Next, the obtained adsorption data were fitted to the Freundlich adsorption isotherm and Langmuir adsorption isotherm. Langmuir adsorption isotherm is applied to the equilibrium adsorption assuming monolayer adsorption onto a surface with a finite number of identical sites.

The Freundlich isotherm model $\left(\mathrm{R}^{2}=0.96\right.$ and 0.97 for $\mathrm{Pb}(\mathrm{II})$ and TCP, respectively) can describe the isotherm better than the Langmuir isotherm model $\left(R^{2}=0.71\right.$ and 0.91$)$. The result suggests that adsorption of $\mathrm{Pb}(\mathrm{II})$ and TCP to TiC ceramics is not the monolayer adsorption onto a surface of $\mathrm{TiC}$ ceramics, and there are several kinds of adsorption pattern between the adsorbates and TiC ceramics. The parameters obtained from the Freundlich isotherm of TiC ceramics are summarized in Table 3, and the parameters obtained from the Freundlich isotherm of adsorbents, which have been previously reported, are also shown in Table 3. The adsorption capacities of TiC ceramics for $\mathrm{Pb}$ (II) and TCP were smaller than those of other adsorbents. On the other hand, the $\mathrm{n}$ value of TiC ceramics for TCP was similar to that of activated carbon. The result suggests that the interaction between TiC ceramics and TCP was as strong as that of activated carbon.

It is considered that the reasons why the adsorption capacities of $\mathrm{TiC}$ ceramics are lower than those of activated carbon are that the surface area of TiC ceramics is smaller and the density of TiC is higher than that of activated carbons. It is expected that the adsorption capacity of TiC ceramics is increased by the change of the Ti:C ratio at the combustion synthesis of the ceramics and the modification of the surface of the material. However, there is a possibility that those reformulations 
may lead to the loss of the persistency in TiC ceramics or the decrease in the recovery of absorbates by elution.

\subsection{Application of TiC ceramics to solid-phase extraction}

For the evaluation of recoveries of Pb(II), TCP, PFOS, and PFOA by SPE using TiC ceramics as an adsorbent, the extraction procedure was carried out after the $500 \mathrm{~mL}$ of distilled water or river water were spiked with 5.0 and $50 \mu \mathrm{g}$ of $\mathrm{Pb}$ (II) or 0.25 and $2.5 \mu \mathrm{g}$ of TCP, PFOS, and PFOA. The adsorbates, $\mathrm{Pb}(\mathrm{II})$, TCP, PFOS, and PFOA, were not detected in distilled water and river water without spiking with the standard solutions.

Table 4 shows relative standard deviation and mean recoveries determined by the recovery test of the distilled water and river water samples spiked with 5.0 and $50 \mu \mathrm{g}$ of $\mathrm{Pb}$ (II) standard solutions. Recoveries (\%) of $\mathrm{Pb}(\mathrm{II})$ by this method were 78 and 96 for $500 \mathrm{~mL}$ of distilled water and river water spiked with $5.0 \mu \mathrm{g}$ of $\mathrm{Pb}$ (II). The relative standard deviations were 4.6 and $5.2 \%$. For the solution spiked with $50 \mu \mathrm{g}$ of $\mathrm{Pb}$ (II), recoveries (\%) of $\mathrm{Pb}$ (II) were 84 and 93 , and the relative standard deviations (\%) were 0.81 and 4.0 , respectively. These results indicate that the solid-phase extraction method using TiC cartridge offers the potential to carry out surveys of $\mathrm{Pb}(\mathrm{II})$, which are present in river water in the $10 \mu \mathrm{g} \mathrm{L}^{-1}$ range. The environment and effluent standards of $\mathrm{Pb}(\mathrm{II})$ in Japan are 10 and $100 \mu \mathrm{g} \mathrm{L} \mathrm{L}^{-1}$, respectively. Therefore, it is considered that TiC cartridge has a potential to be applied to the environmental analysis of $\mathrm{Pb}(\mathrm{II})$.

Next, relative standard deviation and mean recoveries determined by the recovery test of the distilled water and river water samples spiked with 0.25 and $2.5 \mu \mathrm{g}$ of TCP, PFOS, and PFOA standard solutions were summarized in Table 5. The peaks of TCP, PFOS, and PFOA were clearly detected without interferences by peaks of contaminants in the sampled river water. Recoveries (\%) of TCP, PFOS, and PFOA were in the ranges of $89-101(0.25 \mu \mathrm{g}$ of these compounds were spiked in 
$500 \mathrm{~mL}$ of distilled water) and 102-114 (spiked with $2.5 \mu \mathrm{g}$ ), and the relative standard deviations (\%) were in the ranges of 5.9-29 $(0.25 \mu \mathrm{g})$ and $18-25(2.5 \mu \mathrm{g})$. The relative standard deviations were relatively high compared to the case for the extraction of $\mathrm{Pb}(\mathrm{II})$ by $\mathrm{TiC}$ cartridge, though the recoveries showed approximately $100 \%$. Hydrophobic interaction between an adsorbent and an adsorbate is influenced by the surface structure of an adsorbent. As described above, it is considered that $\mathrm{TiC}$ ceramics absorb organic compounds with hydrophobic interaction. Therefore, it is expected that the dispersion of recoveries can be decreased by the further homogenization of the particle size and form of TiC ceramics.

In the case of river water, the recoveries (\%) of TCP, PFOS, and PFOA were in the ranges of 26-58 (0.25 $\mu \mathrm{g}$ of these compounds spiked in $500 \mathrm{~mL}$ of river water) and 65-91 (spiked with 2.5 $\mu \mathrm{g})$, and the relative standard deviations $(\%)$ were in the ranges of 8.9-9.0 $(0.25 \mu \mathrm{g})$ and 14-26 (2.5 $\mu \mathrm{g})$. In the case of $0.25 \mu \mathrm{g}$ of these compounds spiked in $500 \mathrm{~mL}$ of river water, the recoveries were low. When the PFOS spiked solution was passed through TiC cartridge, PFOS was not detected in the obtained solution. The recovery of PFOS ( $0.25 \mu \mathrm{g}$ of PFOS spiked in $500 \mathrm{~mL}$ of river water) was $55 \%$. The elution of PFOS would be interrupted by the influence of environment matrix. On the other hand, when the PFOA spiked solution was passed through TiC cartridge, PFOA was detected in the obtained solution. Therefore, the adsorption rate of PFOA to TiC ceramics was not $100 \%$, but about $70 \%$ (spiked with $2.5 \mu \mathrm{g}$ ). PFOA has a property like a surface acting agent, and the adsorption rate may be decreased by the formation of micell with matrix in the river water.

As a result, it was found that the recovery of the environmental analysis for organic pollutants using TiC cartridge could be influenced by the matrix in the sample. However, it is considered that the TiC cartridge could be applied to the environmental analysis for TCP and PFOS of the water sample containing these compounds at the concentration more than $5.0 \mu \mathrm{g} \mathrm{L}{ }^{-1}$. 


\section{Conclusion}

A novel application of the porous carbide ceramics has been presented in this study. The advantages of the powder of porous $\mathrm{TiC}$ ceramics as an adsorbent are adsorption abilities for both inorganic and organic pollutants, an easy elution of retained compounds by using appropriate solvents, and a good reusability. It is expected that $\mathrm{TiC}$ ceramics is useful for not only the removal and analysis of pollutants but also the extraction of valuable resources, such as rare metals, from environmental or waste water. The material has various potentials to be contributed to the development of water cleanup technology and environmental sciences.

\section{Acknowledgement}

This work was supported by Shinshu University Satellite Venture Business Laboratory (SVBL). This paper is dedicated to the first president, Chotaro Harizuka, on the occasion of 100th anniversary of Faculty of Textile Science and Technology, Shinshu University.

\section{Literature Cited}

(1) D. Sud, G. Mahajan, M. P. Kaur, Agricultural waste material as potential adsorbent for sequestering heavy metal ions from aqueous solution- A review, Biores. Technol., 99 (2008) 6017-6027.

(2) H. Sambe, K. Hoshina, J. Haginaka, Molecularly imprinted polymers for triazine herbicides prepared by multi-step swelling and polymerization method: Their application to the determination of methylthiotriazine herbicides in river water, J. Chromatogr. A, 1152 (2007) 130-137.

(3) T. Budinova, N. Petrov, J. Parra, V. Baloutzov, Use of an activated carbon from antibiotic waste for the removal of $\mathrm{Hg}$ (II) from aqueous solution, J. Environ. Manage., 88 (2008) 165-172. 
(4) C. Namasivayam, D. Sangeetha, Recycling of agricultural solid waste, coir pith: Removal of anions, heavy metals, organics and dyes from water by adsorption onto $\mathrm{ZnCl}_{2}$ activated coir pith carbon, J. Hazard. Mater., 135 (2006) 449-452.

(5) E. Gonzalez-Serrano, T. Cordero, J. Rodriguez-Mirasol, L. Cotoruelo, J. J. Rodriguez, Removal of water pollutants with activated carbons prepared from $\mathrm{H}_{3} \mathrm{PO}_{4}$ activation of lignin from kraft black liquors, Water Res., 38 (2004) 3043-3050.

(6) H. Zhang, Regeneration of exhausted activated carbon by electrochemical method, Chem. Eng. J., 85 (2002) 81-85.

(7) M. Karve, R. V. Rajgor, Solid phase extraction of lead on octadecyl bonded silica membrane disk modified with Cyanex 302 and determination by flame atomic absorption spectrometry, J. Hazard. Mater., 141 (2009) 607-613.

(8) M. A. Salam, R. Burk, Novel application of modified multiwalled carbon nanotubes as a solid phase extraction adsorbent for the determination of polyhalogenated organic pollutants in aqueous solution, Anal. Bioanal. Chem., 390 (2008) 2159-2170.

(9) H. Moriwaki, H. Harino, H. Hashimoto, R. Arakawa, T. Ohe, T. Yoshikura, Determination of aromatic amine mutagens, PBTA-1 and PBTA-2, in river water by solid-phase extraction followed by liquid chromatography-tandem mass spectrometry, J. Chromatogr. A, 995(1-2), (2003) 239-243.

(10) L. Kantiani, M. Farré, M. Sibum, C. Postigo, M. López de Alda, D. Barceló, Fully automated analysis of $\beta$-lactams in bovine milk by online solid phase extraction-liquid chromatography-electrospray-tandem mass spectrometry, Anal. Chem., 81 (2009) 4285-4295.

(11) D. Djozan, B. Ebrahimi, Preparation of new solid phase micro extraction fiber on the basis of atrazine-molecular imprinting polymer: Application for GC and GC/MS screening of triazine herbicides in water, rice and onion, Anal. Chim. Acta, 616 (2008) 152-159. 
(12) M. Quinto, G. Spadaccino, C. Palermo, D. Centonze, Determination of aflatoxins in cereal flours by solid-phase microextraction coupled with liquid chromatography and post-column photochemical derivatization-fluorescence detection, J. Chromatogr. A, 1216 (2009) 8636-8641.

(13) D. A. Pratt, Y. Daniloff, A. Duncan, S. P. Robins, Automated analysis of the pyridinium crosslinks of collagen in tissue and urine using solid-phase extraction and reversed-phase high-performance liquid chromatography, Anal. Biochem., 207 (1992) 168-175.

(14) E. H. M. Koster, C. Crescenzi, W. den Hoedt, K. Ensing, G. J. de Jong, Fibers coated with molecularly imprinted polymers for solid-phase microextraction, Anal. Chem. 73 (2001) $3140-3145$

(15) H. Moriwaki, A. Watanabe, R. Arakawa, Y. Tsujimoto, M. Shimizu, T. Noda, M. Warashina, M. Tanaka, Simultaneous determination of metabolites of trimethylbenzenes, dimethylbenzylmercapturic acid and dimethylhippuric acid, in human urine by solid-phase extraction followed by liquid chromatography-tandem mass spectrometry, J. Mass Spectrom., 37 (2002) 1152-1157.

(16) M.-C. Hennion, Solid-phase extraction: method development, sorbents, and coupling with liquid chromatography, J. Chromatogr. A, 856 (1999) 3-54.

(17) M. J. Wirth, H. O. Fatunmbi, Polymeization of mixed trifunctional silanes on silica. 2. Application to chromatographic silica gel, Anal. Chem. 65 (1993) 822-826.

(18) J. J. Kirkland, J. W. Henderson, J. J. DeStefano, M. A. van Straten, H. A. Claessens, Stability of silica-based, endcapped columns with pH 7 and 11, J. Chromatogr A, 762 (1997) 97-112.

(19) S. Adachi, T. Wada, T. Mihara, Y. Miyamoto, M. Koizumi, O. Yamada, Fabrication of titanium carbide ceramics by high-pressure self-combustion sintering of titanium powder and carbon fiber, J. Am. Ceramics Soc. 72 (1989) 805-809.

(20) J. H. She, Z. Y. Deng, J. Daniel-doni, T. Ohji, Oxidation bonding of porous silicon carbide 
ceramics, J. Mater. Sci. 37 (2002) 3615-3622.

(21) C.R. Rambo, J. Cao, O. Rusina, H. Sieber, Manufacturing of biomorphic (Si, Ti, Zr)-carbide ceramics by sol-gel processing, Carbon, 43 (2005) 1174-1183.

(22) O. Yamada, Y. Miyamoto, M. Koizumi, High-pressure self-combustion sintering of titanium carbide, J. Am. Ceramic Soc., 70 (1987) C206-C208.

(23) A. Sayir, Carbon fiber reinforced hafnium carbide composite, J. Mater. Sci. 39 (2004) 5995-6003.

(24) S. Gomez-Salazar, J. S. Lee, J. C. Heydweiller, L. L. Tavlarides, Analysis of cadmium adsorption on novel organo-ceramic adsorbent with a thiol functionality, Ind. Eng. Chem. Res., 42 (2003) 3403-3412.

(25) R. Allabashi, M. Arkas, G. Hörmann, D. Tsiourvas, Removal of some organic pollutants in water employing ceramic membranes impregnated with cross-linked silylated dendritic and cyclodextrin polymers, Water Res., 41 (2007) 476-486.

(26) J. Fan, C. Wu, H. Xu, J. Wang, C. Peng, Chemically functionalized silica gel with alizarin violet and its application for selective solid-phase extraction of lead from environmental samples, Talanta, 74 (2008) 1020-1025.

(27) D. A. Hirschfeld, T. K. Li, D. M. Liu, Processing of porous oxide ceramics, Key Eng. Mater., 115 (1996) 65-80.

(28) M.-W. Jung, K.-H. Ahn, Yo. Lee, K.-P. Kim, J.-S. Rhee, J. T. Park, K.-J. Paeng, Adsorption characteristics of phenol and chlorophenols on granular activated carbons (GAC), Microchem. J., 70 (2001)123-131.

(29) C. Pelekani, V. L. Snoeyink, Competitive adsorption between atrazine and methylene blue on activated carbon: the importance of pore size distribution, Carbon, 38 (2000) 1423-1436.

(30) P.C. Mishra, R.K. Patel, Removal of lead and zinc ions from water by low cost adsorbents, J. 
Hazard. Mater., 168 (2009) 319-325.

(31) I.A.W. Tan, A.L. Ahmad, B.H. Hameed, Adsorption isotherms, kinetics, thermodynamics and desorption studies of 2,4,6-trichlorophenol on oil palm empty fruit bunch-based activated carbon J. Hazard. Mater., 164 (2009) 473-482.

\section{Figure captions}

Fig.1 Scanning electron micrograph of TiC ceramics (x 180)

Fig. 2 Adsorption and elution of $\mathrm{Pb}(\mathrm{II})$ by TiC cartridge

(Initial Pb(II) concentration: $10 \mu \mathrm{g} / \mathrm{mL}$; adsorbent loading $2.0 \mathrm{~g} / 10 \mathrm{~mL}$ )

Fig.3 Adsorption and elution of PFOS by TiC cartridge

(Initial PFOS concentration: $10 \mu \mathrm{g} / \mathrm{mL}$; adsorbent loading $2.0 \mathrm{~g} / 10 \mathrm{~mL}$ )

Fig.4 Adsorption isotherm of $\mathrm{Pb}(\mathrm{II})$ to TiC ceramics

Fig.5 Adsorption isotherm of TCP to TiC ceramics 


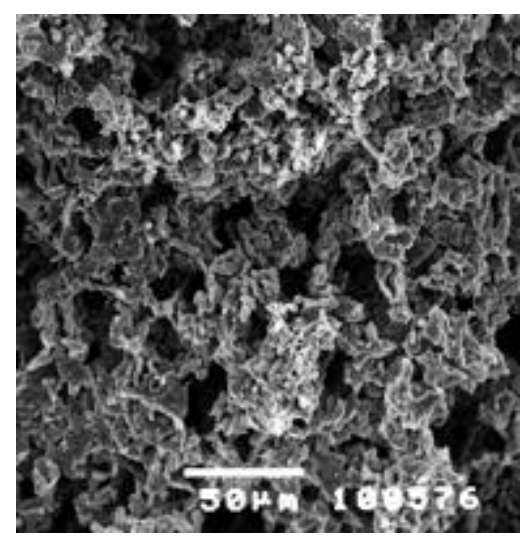

Fig.1 


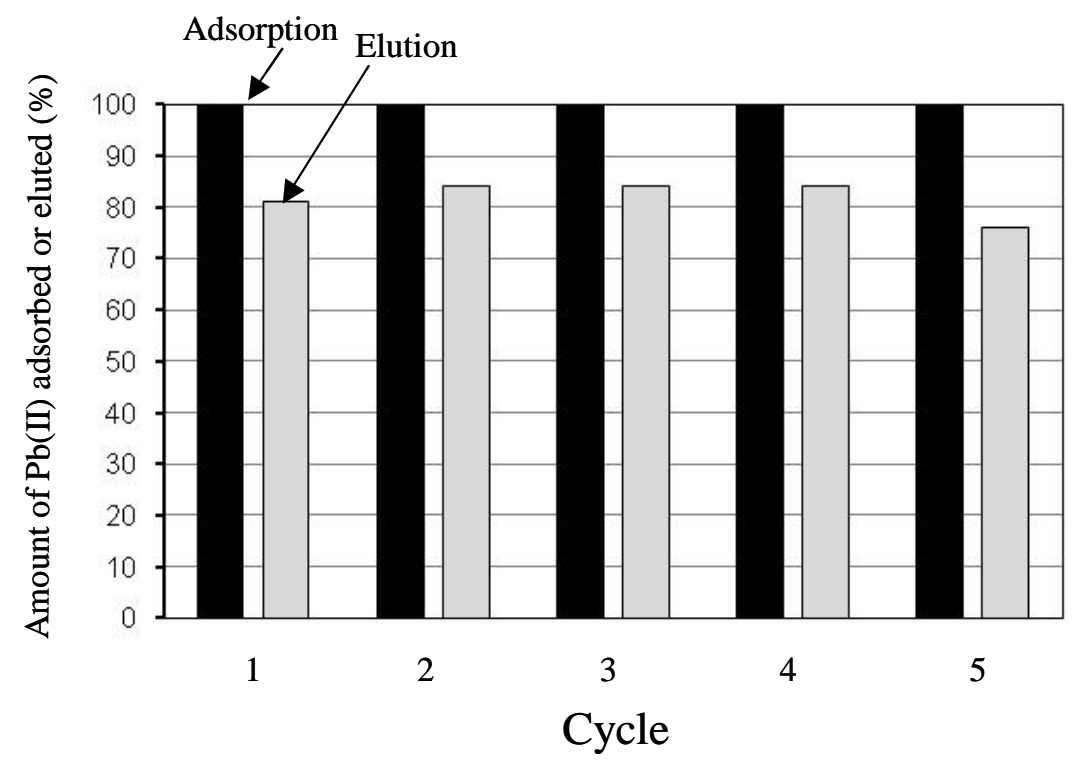

Fig. 2 


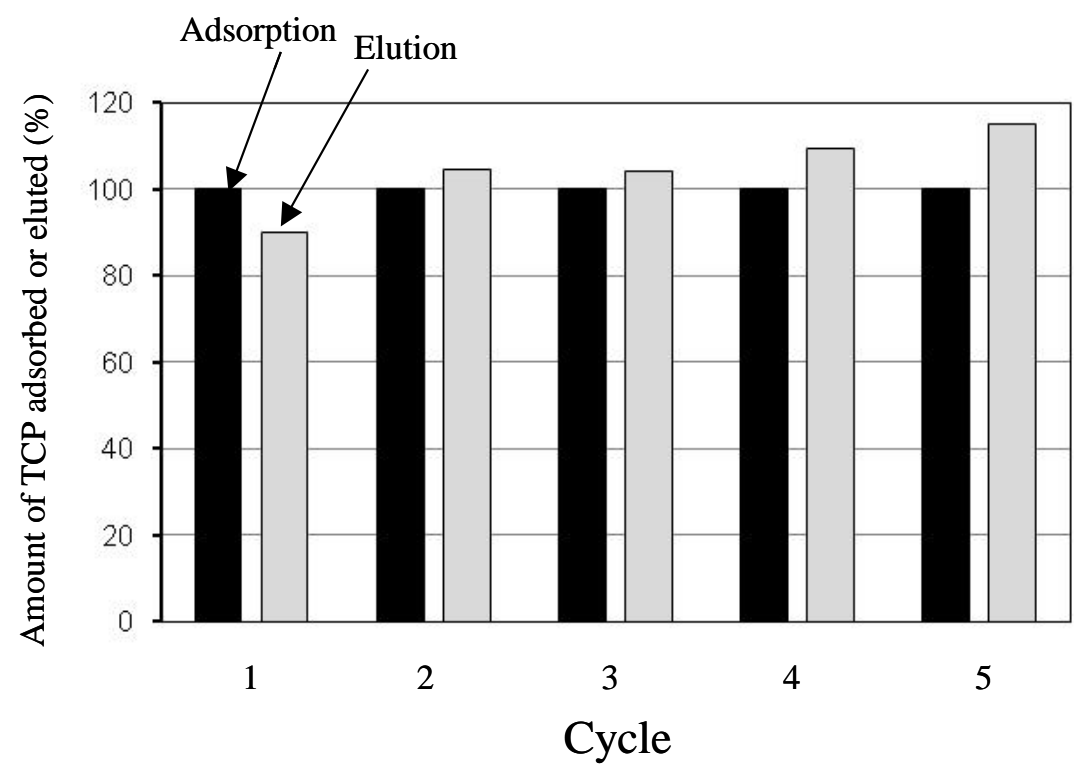

Fig. 3 


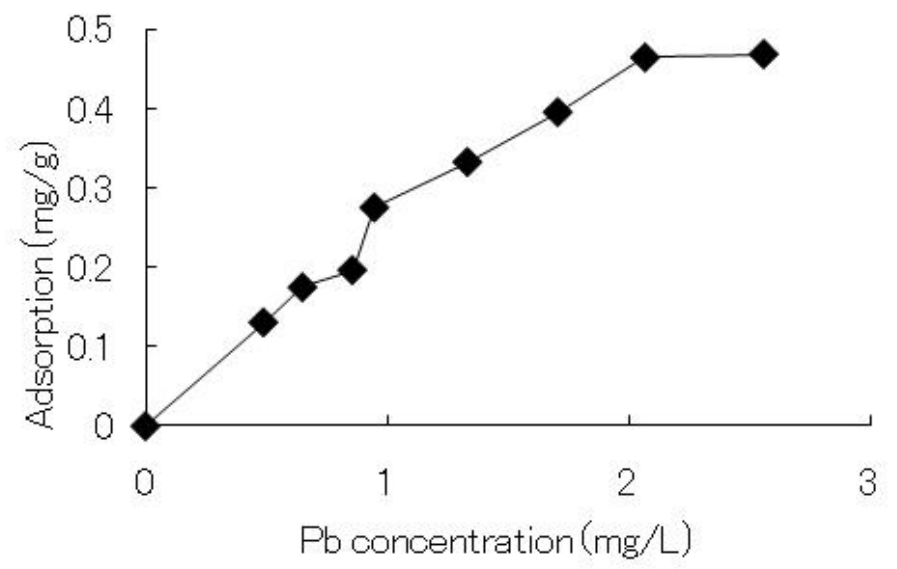

Fig. 4 


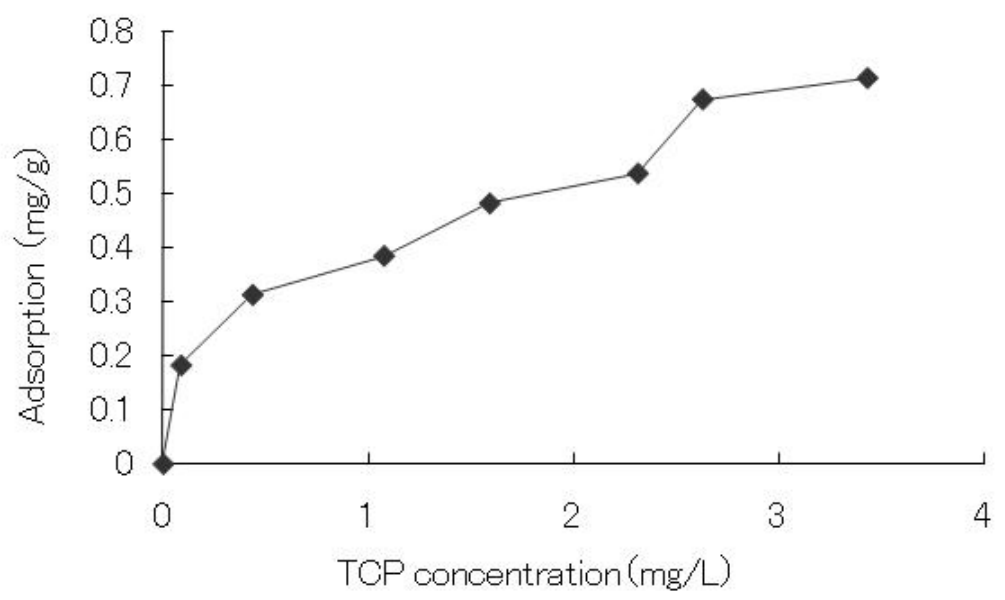

Fig. 5 


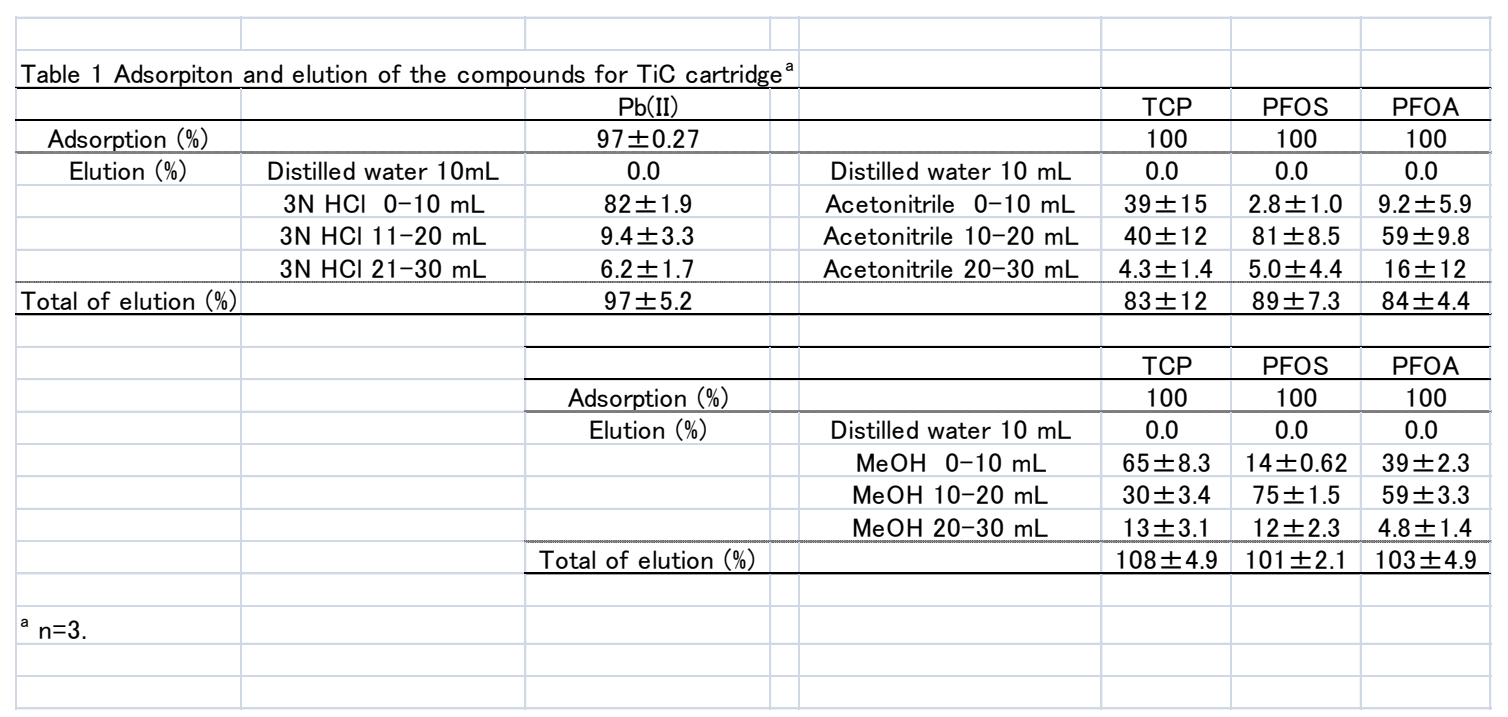

Table 2 Adsorpiton and elution of the compounds for AC2 cartridge ${ }^{a}$

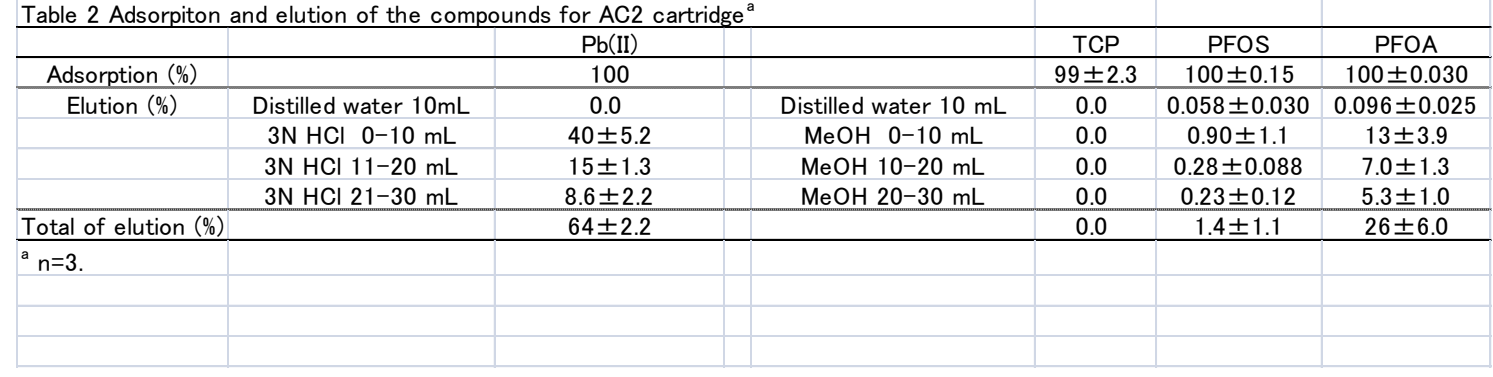

\begin{tabular}{|c|c|c|c|c|c|c|}
\hline \multirow[t]{2}{*}{ Adsorbent } & \multirow[t]{2}{*}{ Adsorbate } & \multicolumn{3}{|c|}{ Freundlich parameter } & \multirow{2}{*}{$\begin{array}{c}\text { Specific surface } \\
\text { area }\left(\mathrm{m}^{2} / \mathrm{g}\right)\end{array}$} & \multirow[t]{2}{*}{ Ref } \\
\hline & & $\mathrm{K}_{\mathrm{F}}\left(\mathrm{mg} / \mathrm{g}(\mathrm{L} / \mathrm{mg})^{1 / \mathrm{n}}\right)$ & $\mathrm{n}$ & $r^{2}$ & & \\
\hline Activated carbon & $\mathrm{Pb}$ & 0.85 & 2.27 & 0.87 & 655.44 & [30] \\
\hline Bnetonite & $\mathrm{Pb}$ & 17.98 & 1.19 & 0.95 & 62.69 & [30] \\
\hline Fly ash & $\mathrm{Pb}$ & 1.92 & 4.34 & 0.97 & 0.75 & [30] \\
\hline TiCceramics & $\mathrm{Pb}$ & 0.248 & 1.23 & 0.96 & 2.77 & This study \\
\hline \multicolumn{7}{|l|}{ Activated carbon prepared from } \\
\hline oil palm empty fruit bunch & TCP & 22.04 & 1.25 & 0.998 & - & [31] \\
\hline TiCceramics & TCP & 0.42 & 2.75 & 0.97 & 2.77 & This study \\
\hline
\end{tabular}


Table 4 Recovery of $\mathrm{Pb}$ (II) from distilled water and river water $(500 \mathrm{~mL})^{\mathrm{a}}$

\begin{tabular}{|c|c|c|c|}
\hline Fraction & $\begin{array}{c}\text { Spiked quantity of } \\
\mathrm{Pb}(\mu \mathrm{g})\end{array}$ & Solution & Recovery (\%) \\
\hline $3 \mathrm{~N} \mathrm{HCl} 0-10 \mathrm{~mL}$ & 50 & Distilled water $500 \mathrm{~mL}$ & $80 \pm 0.81$ \\
\hline $3 \mathrm{~N} \mathrm{HCl} 10-20 \mathrm{~mL}$ & 50 & Distilled water $500 \mathrm{~mL}$ & $3.1 \pm 0.13$ \\
\hline $3 \mathrm{~N} \mathrm{HCl} 20-30 \mathrm{~mL}$ & 50 & Distilled water $500 \mathrm{~mL}$ & $0.99 \pm 0.21$ \\
\hline total & - & - & $84 \pm 0.81$ \\
\hline $3 \mathrm{~N} \mathrm{HCl} \quad 0-10 \mathrm{~mL}$ & 5.0 & Distilled water $500 \mathrm{~mL}$ & $78 \pm 4.6$ \\
\hline $3 \mathrm{~N} \mathrm{HCl} 10-20 \mathrm{~mL}$ & 5.0 & Distilled water $500 \mathrm{~mL}$ & 0 \\
\hline $3 \mathrm{~N} \mathrm{HCl} 20-30 \mathrm{~mL}$ & 5.0 & Distilled water $500 \mathrm{~mL}$ & 0 \\
\hline total & - & - & $78 \pm 4.6$ \\
\hline $3 \mathrm{~N} \mathrm{HCl} 0-10 \mathrm{~mL}$ & 50 & River water $500 \mathrm{~mL}$ & $90 \pm 4.3$ \\
\hline $3 \mathrm{~N} \mathrm{HCl} 10-20 \mathrm{~mL}$ & 50 & River water $500 \mathrm{~mL}$ & $2.1 \pm 0.36$ \\
\hline $3 \mathrm{~N} \mathrm{HCl} 20-30 \mathrm{~mL}$ & 50 & River water $500 \mathrm{~mL}$ & $0.74 \pm 0.27$ \\
\hline total & - & - & $93 \pm 4.0$ \\
\hline $3 \mathrm{~N} \mathrm{HCl} \quad 0-10 \mathrm{~mL}$ & 5.0 & River water $500 \mathrm{~mL}$ & $96 \pm 5.2$ \\
\hline $3 \mathrm{~N} \mathrm{HCl} 10-20 \mathrm{~mL}$ & 5.0 & River water $500 \mathrm{~mL}$ & 0 \\
\hline $3 \mathrm{~N} \mathrm{HCl} 20-30 \mathrm{~mL}$ & 5.0 & River water $500 \mathrm{~mL}$ & 0 \\
\hline total & - & - & $96 \pm 5.2$ \\
\hline & & & \\
\hline
\end{tabular}

Table 5 Recovery of TCP, PFOA, and PFOS from distilled water and river water $(500 \mathrm{~mL})^{\mathrm{a}}$

\begin{tabular}{|c|c|c|c|c|c|c|c|}
\hline \multirow[t]{2}{*}{ Fraction } & \multirow[t]{2}{*}{ Solution } & \multicolumn{6}{|c|}{ Recovery (\%) } \\
\hline & & TCP $(2.5 \mu \mathrm{g})$ & PFOS $(2.5 \mu \mathrm{g})$ & PFOA $(2.5 \mu \mathrm{g})$ & TCP $(0.25 \mu \mathrm{g})$ & PFOS $(0.25 \mu \mathrm{g})$ & PFOA $(0.25 \mu \mathrm{g})$ \\
\hline $\mathrm{MeOH} \quad 0-10 \mathrm{~mL}$ & Distilled water $500 \mathrm{~mL}$ & $45 \pm 12$ & $59 \pm 31$ & $75 \pm 31$ & $22 \pm 7.8$ & $59 \pm 25$ & $72 \pm 21$ \\
\hline $\mathrm{MeOH} 10-20 \mathrm{~mL}$ & Distilled water $500 \mathrm{~mL}$ & $33 \pm 19$ & $54 \pm 8.5$ & $34 \pm 8.8$ & $45 \pm 5.6$ & $38 \pm 5.7$ & $28 \pm 6.9$ \\
\hline $\mathrm{MeOH} 20-30 \mathrm{~mL}$ & Distilled water $500 \mathrm{~mL}$ & $8.1 \pm 3.2$ & $0.76 \pm 0.73$ & $0.73 \pm 0.38$ & $23 \pm 7.6$ & $0.58 \pm 0.032$ & $1.1 \pm 0.20$ \\
\hline total & - & $102 \pm 18$ & $114 \pm 25$ & $110 \pm 22$ & $89 \pm 5.9$ & $98 \pm 29$ & $101 \pm 24$ \\
\hline $\mathrm{MeOH} \quad 0-10 \mathrm{~mL}$ & River water $500 \mathrm{~mL}$ & $91 \pm 14$ & $90 \pm 16$ & $65 \pm 26$ & $58 \pm 9.0$ & $54 \pm 9.0$ & $23 \pm 7.0$ \\
\hline $\mathrm{MeOH} 10-20 \mathrm{~mL}$ & River water $500 \mathrm{~mL}$ & 0 & $0.84 \pm 0.42$ & $0.58 \pm 0.17$ & 0 & $0.50 \pm 0.12$ & $2.2 \pm 2.9$ \\
\hline $\mathrm{MeOH} 20-30 \mathrm{~mL}$ & River water $500 \mathrm{~mL}$ & 0 & $0.12 \pm 0.013$ & $0.27 \pm 0.029$ & 0 & $0.25 \pm 0.021$ & $0.42 \pm 0.096$ \\
\hline total & - & $91 \pm 14$ & $91 \pm 17$ & $65 \pm 26$ & $58 \pm 9.0$ & $55 \pm 9.0$ & $26 \pm 8.9$ \\
\hline & & & & & & & \\
\hline
\end{tabular}

